\title{
Exploring Drama as an Additional Language through Research-based Theatre
}

\author{
Amanda Wager; George Belliveau; Jaime Beck; Graham W. \\ Lea
}

\begin{abstract}
This article explores the social, cultural, and emotional learning that occurred when drama was used with a group of native English speakers and English Language Learners (ELL) to build community. These learners consisted of university Drama in Education students who led a group of elementary students in an after-school drama program in Vancouver, Canada. University of British Columbia (UBC) researchers investigated the potential that drama has to build community with learners from multiple backgrounds and ages. The researchers also examined the potential that theatre methods have to analyze and represent findings discovered within the research data. In reflecting upon the learning that supported the community building, three themes were identified within the data: process and product, negotiation and conflict, and the building of community. ELL Program Leaders' journals were used as data to explore the Program Leaders' perspectives of how the drama program influenced their language acquisition skills and cultural understanding. As the data were analyzed, the researchers transformed recurring themes and significant findings into a dramatic text. This text, created and performed by the researchers at multiple conferences, is integrated into the article. Reflections from the researchers are also shared, along with insights gained while developing and presenting their research-based theatre piece.
\end{abstract}

\section{Introduction: The Building of Community}

In a time long past, there dwelt a gentle people who were in harmony with their land and with each other. . . . A tradition they treasured, was to gather together in celebration of the blessings of the community with thanksgiving, joy, music and laughter. Everyone lived happily, respecting each other. (excerpt from The Gentle People, an Argentinean Folktale, quoted in Raczuk \& Smith 2000: 25) 
In the spring of 2008, a group of elementary students at Cedar Springs Elementary ${ }^{1}$ in Vancouver, Canada celebrated their participation in an afterschool drama program with their final performance of The Gentle People. The program was led by University of British Columbia (UBC) students, referred to in this paper as Program Leaders, who were taking a Drama in Education course that explored approaches of integrating drama into the elementary curriculum (Bowell \& Heap 2001; Fels \& Belliveau 2008: 43). The Cedar Springs students and the Program Leaders formed a diverse cultural and linguistic community comprised of both English Language Learner (ELL) and non-ELL participants (see Fig. 1). The after-school program was part of a larger social justice and drama research project funded by the Social Sciences and Humanities Research Council of Canada (SSHRC) led by Dr. George Belliveau. The central question raised within the research project considers the efficacy of drama as a vehicle through which socially responsible behaviour can be enhanced. The research focus of this paper is to investigate the impact that drama has on community building when multicultural and multilingual learners are represented. The use of drama to enhance language comprehension and cultural understanding is also examined as theoretical stepping-stones to community building. In an effort to illuminate the multiple perspectives and unique challenges of both ELL and non-ELL participants in the after-school drama program the authors used research-based theatre as a methodology (Mienczakowski \& Moore 2008: 451, Norris 2000).

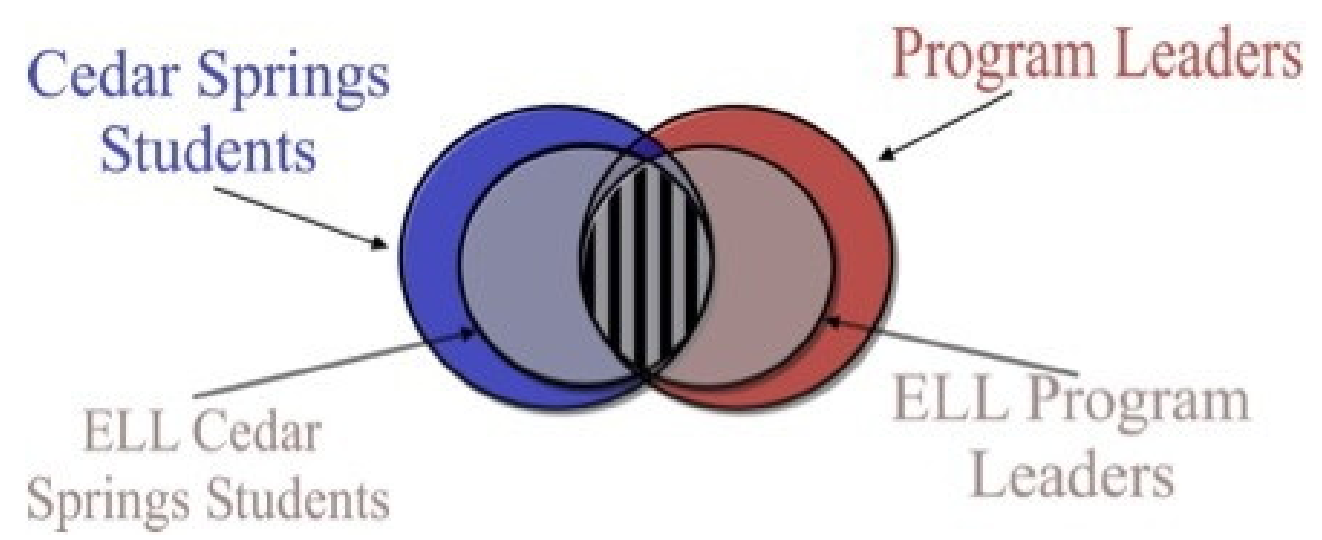

Figure 1: The intersection of ELL students and Program Leaders within the afterschool drama program

\section{Literature and Theory: Drama as an Additional Language}

Drama as a strategy to enhance learning has been practiced, or at least written about, in the Western world for nearly a century. Educational drama can be

\footnotetext{
${ }^{1}$ To protect the identity of participants, pseudonyms are used for the school and all individuals.
} 
traced to the work of Henry Caldwell Cook (1917) who developed the Play Way approach, a strategy that encourages primary and secondary students to practice both language and social skills. Since Cook's early writings a number of researchers, practitioners, and educators have shared approaches on how drama facilitates learning (Ward 1930; Slade 1954; Way 1967; Bolton 1979; Bolton 1984; Heathcote \& Bolton 1995; O'Neill 1995 - to name a few).

More recently, a group of researchers and educators have begun to investigate ways in which drama increases engagement in language learning and facilitates comprehension skills (Catterall 2002; Dodson 2000; Wagner 1998). The work of these researchers, among others, suggests that drama-based activities improve literacy skills, reaching students with a range of language abilities (Miccoli 2003: 128). More specifically, studies have documented how language learning through drama has positively influenced vocabulary development, as well as increased agility, fluency, and flexibility of language use (Dodson 2000: 131). In the introduction to Body and Language: Intercultural Learning Through Drama, a seminal work in the field of drama and foreign language learning, editor Gerd Bräuer (2002) notes how drama has the potential to emphasize language fluency through improvisation as well as to develop accuracy through script memorization or repeated reading practice. Developing both fluency and accuracy supports the notion of process-driven and product-driven drama activities being both equally viable and mutually beneficial opportunities for language development.

Adding another layer to the development of drama and foreign language learning, Bournot-Trites et al. (2007) point out, in their study of grade six and seven French language learners, how "drama offers a social context in which to use and learn language" (2007: 11). The opportunity to explore a foreign language within a social context through drama-based strategies was found to increase students' motivation as well as fluency in the target language (Bournot-Trites et al. 2007). Exploring social contexts through drama engages learners in a dialogue that enables them to understand themselves and the world they live in (O'Neill 1995).

Educational theorists such as Bruner (1996), Freire (1998), and Vygotsky (1978) describe children as being culturally cultivated prior to entering school. These theorists argue that children are shaped by the environment in which they are raised, while simultaneously constructing meaning from this environment. This approach to constructivist thinking foregrounds the notion that learners construct knowledge in order to conceive it. Children are not empty vessels, but rather astute "thinkers and language-users" (Donaldson 1978: 121) able "to reason, to make sense, both on [their] own and through discourse with others" (Bruner 1996: 57).

In their theorizing both Vygotsky and Bruner indicate that play (which includes drama) facilitates learning in many different subject areas, as it provides opportunities to co-construct knowledge thus expanding and deepening understanding of the topics being explored. Play can also create a new space from which a hybridity of cultures is formed within classrooms 
(Axtmann 2002: 38). In multicultural classrooms, it is vital that approaches for creating these spaces be made available to educators in order to "further students' language skills and to explore and address issues that will . . . affect all our lives . . . on a more global scale" (Schewe 2002: 89). Within his work on community development through drama, Rohd supports the integral nature of drama as it "allows us . . . to passionately pursue and discover ways of living with ourselves and others . . . theatre [drama] is a language" (Rohd 1998: xix). Building on these ideas, we use the phrase Drama as an Additional Language as a metaphor to describe the ways in which participants in this study experienced communication through drama, communication that ultimately led to the creation of a community.

\section{Methodology: Research-based Theatre}

The methodological approach in this study builds on the work of Saldaña (1999; 2003; 2005) and Norris (2000), in that research-based theatre was used to both analyse and disseminate the data. This arts-based approach to research allowed the authors to show rather than tell the understandings gained through their research explorations. Salient moments within the data were isolated and developed into short dramatic scenes to vividly depict the participants' lived experiences (Saldaña 2005). These scripted scenes were explored and performed theatrically (Norris 2000) creating a complex space co-inhabited by the Program Leaders, elementary students, and the authors/researchers (see Fig.2). The scenes created through this space were woven with PowerPoint explanations of the research process to become Drama as an Additional Language, which was presented for academic audiences. ${ }^{2}$ Script excerpts from these presentations are integrated throughout this article. However, since the performances used the script scenes as starting points, the excerpts are only representations of the performances, reinforcing the nature of this research as a reflection of the data, not a fixed "ethnographic truth" (Goldstein 2001: 294).

\section{Program, Participants, and Data Collection}

Approximately $40 \%$ of the elementary students and $33 \%$ of the Program Leaders were identified as ELL participants (see Fig. 3). The 22 Program Leaders were either in the process of becoming teachers or were already teachers in Canada or abroad. Seven of the Program Leaders were exchange students living on the university campus.

\footnotetext{
2 The performed presentation was shared with three different audiences within Canada in March, 2009: Department of Language and Literacy research series, UBC, Vancouver, BC; International Association for Performing Language conference in Victoria, BC; and a/r/tography research seminar, UBC, Vancouver, BC.
} 


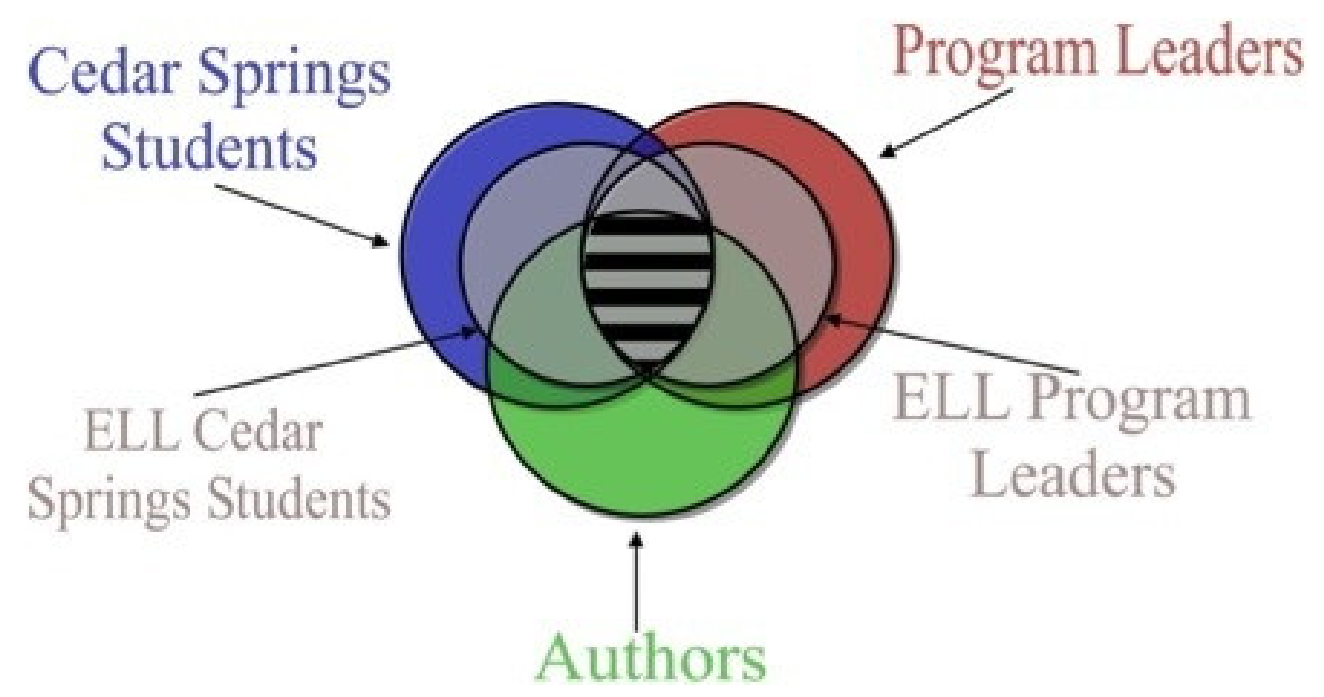

Figure 2: The Intersection of Participants in Drama as an Additional Language
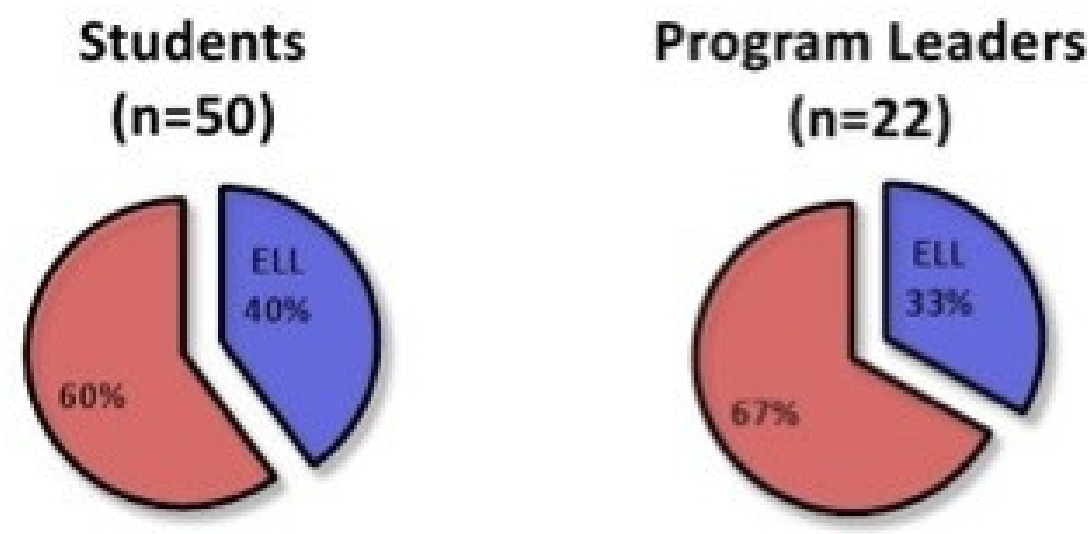

Figure 3: Population of ELL Students and Program Leaders

The elementary students in the after-school drama program were led in small groups through a variety of drama activities; including 'pass the energy,' in which an imaginary ball of energy is passed around, and the 'scarf game,' in which participants imaginatively transformed a scarf into an object of their choosing. The students were also engaged in dramatic readings and performances of poetry, such as On the Day You Were Born by Debra Frasier (1991) and The Gentle People an Argentinean folktale (in Raczuk \& Smith 2000: 25). Parents were invited to both observe the process and attend the dramatizations of the poems presented during the program.

Program Leaders were enrolled in a Drama in Education course at the University of British Columbia. One of the requirements of the course was to help lead the after-school drama program and to keep a journal in which they would reflect on course activities, readings, and their experiences at Cedar Springs. These journals were the primary data for this study, supplemented by 
researcher field observations, photos, videos, and student surveys.

The analysis consisted of the authors individually reading Program Leader journals, noting three emergent themes: process and product, negotiation and conflict, and building community (Hsieh \& Shannon 2005: 1277). The authors also noted a few outlying experiences that were not categorized within the three themes, but were significant to understanding the experience. The researchers shared their findings with one another both through discussion and artistic representation by scripting and improvising scenes (Norris 2000). These improvised scenes were further developed by the researchers through the use of a Wiki, a collaborative online writing tool. Using the scripted scenes as a basis, the researchers continued to analyze the data through improvisation, rehearsal, and performance. The presentation Drama as an Additional Language evolved through this recursive process of artistic engagement with the data (Irwin \& Springgay 2009: xxix).

\section{Theme A: Process and Product}

A common point of discussion among the Program Leaders in the Drama in Education course was the conflicting/complementary roles of process and product in drama. Throughout the course, the instructor focused on the process of drama as a means to both teach about and develop community (Rohd 1998). Some of the Program Leaders, particularly those who were experienced classroom teachers, expected a more product-oriented approach and therefore there was a great deal of reflection on this tension in their journals. However, shifts in beliefs towards the value of the process and deep reflection on the continued importance of the final product were also observed.

One Program Leader reflected on a changing understanding of the relationship between process and product recognizing that "this is something I am going to have to work on, realizing that it is ok not to have a final product, that the process should be just as rewarding or even more so" (Rachel, Program Leader journal 2008). ${ }^{3}$ Others were even more struck by the process, one commenting that "the 'magic' that happens during the process is much more meaningful than a final product. I hate how teachers are forced to focus on the product, e.g. standardized tests" (Sandra, Program Leader journal 2008).

While process became important for the Program Leaders, the final performance, the product, also enriched the program by setting a collective goal. One Program Leader commented that "I like the idea of product because I find it is much more motivating for my students and myself . . . to perfect a polished piece" (Jackie, Program Leader journal 2008). Furthering students' motivation to polish the piece, parents were invited into the community to watch the final production. "Eye contact between kids and their parents before the performance affected [the performance] - [the students] conducted their role considerably better during the performance" (Mandy, Program Leader

\footnotetext{
${ }^{3}$ Program Leader journal entries are from the raw data of Belliveau, et. al.'s 2008 study.
} 
journal 2008). This interaction between parents, students, and Program Leaders created a heightened sense of unity and community on the final day.

\section{Theme B: Negotiation and Conflict}

Below is an excerpt from the authors' scripted analysis that reflects insights into the Program Leaders' experience of conflict and their negotiation of it. Ji-Soo and M.J. (both ELL participants) and Kathryn (a non-ELL participant) are composite characters based on Program Leaders in the after-school drama program. Gary represents the professor of the Drama in Education course.

JI-SOO: ${ }^{4}$ (sitting on the bus - to audience) We would be speaking Korean to each other right now. (to M.J.) I am so nervous to be in this new country. Today is my first time leaving campus. There is so much difference here.

M.J.: (sitting next to JI-SOO on the bus) It makes me think of Korea differently being here.

JI-SOO: It makes you realize the difference in values too . .

M.J.: It is good that we are going to this school in Vancouver. We will get real life experience teaching here.

JI-SOO: Yes, but I am so nervous. Do you think we are on the right bus?

M.J.: (looking around) I have no idea.

(Meanwhile, Kathryn is at the school waiting for class to begin.)

KATHRYN: More than half the class is late. I am exhausted from teaching my first grade French immersion class today. I can't believe that I have to teach all day and then come to another school and teach again. I just want to be on my couch.

JI-SOO: (Entering - confused) Hello. Sorry we're late.

M.J.: We got on the wrong bus - it's our first time this far away from campus.

This short scene, developed during the script writing and improvisational data analysis, illustrates a tension created by the inconsistency of some Program Leaders who were sometimes late or absent. The late and absent Program Leaders forced their peers to make on-the-spot revisions of planned lessons. While many of the novice Program Leaders were keen to learn from the spontaneity and flexibility demonstrated by the more experienced teachers as they improvised new lesson plans, their journals indicate that tensions did arise, and that solutions were created.

I was a little frustrated today . . . to plan the opening games and exercises . . . it was a little hazy as to who would do what. I found that I wanted to take a step back and give my partner more opportunities to take the lead but I don't think she was comfortable doing that . . . I set up the situation so that she would feel more comfortable by suggesting an activity for her to try. (Jackie, Program Leader journal 2008)

\footnotetext{
${ }^{4}$ Scripted sections are representations of the research-based theatre performance Drama as an Additional Language.
} 
While guiding small groups, the Program Leaders continuously negotiated their roles. Noting that "[my partner] has more actual teaching experience," one of the Program Leaders decided to "let her lead a lot and [I] only took over when I was given the opportunity. I will take more control next week" (Kathleen, Program Leader journal 2008).

Despite the tension, mutual respect and social responsibility seemed to grow among Program Leaders through their shared desire for the elementary students to lead their own learning process: "[my partner] and I agreed that students have to have many chances to lead their own learning process. . . . They surely had brilliant ideas" (Yeun-ja, Program Leader journal 2008). Below is a scripted example of when students took the lead, suggesting the use of musical instruments to enhance their poetry dramatizations:

GARY: Something quite unique happened in one of the groups as we rehearsed the poem The Gentle People. A number of the kids who seemed uncomfortable reading -

JI-SOO: chose instruments instead of speaking lines -

M.J.: The instruments became their voices (as she picks up an instrument).

GARY: The instruments allowed everyone to get involved.

KATHRYN: The instruments made for a beautiful scene.

The Program Leaders were able to integrate the use of music into the drama. This provided an increased depth, without spoken language, to the production and the evolving community.

\section{Theme C: Building Community}

Within the Program Leader journals there were often data that represented the building of community. The community that evolved as part of the after-school drama program took time to develop (McKean 2006; Rohd 1998), yet excitement and engagement gently built over the two-month period. At first Program Leaders found it overwhelming to use drama with a range of new students, as Rachel points out: "it [was] a little difficult to begin drama with students [we were] unfamiliar with" (Rachel, Program Leader journal 2008). Initially, the students were placed in mixed-age groups ranging from grades one to seven; however, this wide age range made it difficult to create an environment suitable to all participants. One group, having only one older student, found it challenging to bridge age gaps in order to find "ways to make him feel included and wanting to participate" (Kathleen, Program Leader journals 2008). To overcome the obstacle created by the wide distribution of ages, the Program Leaders re-organized the students into homogeneous age groups.

The community building process began through interactions within the small groups, and developed further as these groups "worked together to form a greater community working together for a common benefit [the final presentation]. Much like the function of real communities" (Sanya, Program Leader journal 2008). Many students would help other students in different 
groups, depending on their reading levels, ages, and language abilities. These communities were nurtured as participants and Program Leaders cultivated an appreciation and social awareness for each other by sharing their drama activities: "doing activities together, students will realize the worth of each person" (Kayoung, Program Leader journal 2008).

The drama activities also provided opportunities for students to reflect upon their local communities outside of school, as students would "brainstorm about what a community meant to them. After some discussion the children finally got the hang of what a community was and could relate the concept to houses, parks, libraries, and community centres around where they lived" (Sanya, Program Leader journal 2008). These conceptualizations of communities were explored dramatically through activities such as tableaux. The tableaux created by the students included those representing school, family, and places of worship. Through this and similar activities, students were able to construct representations of their multicultural backgrounds and gain insight into each other's cultural heritage.

The multicultural and multilingual nature of the group of Program Leaders did contribute to some self-doubt, as expressed by ELL Program Leaders below in the scripted data, with respect to their English proficiency:

(Several students are seated around KATHRYN and JI-SOO)

KATHRYN: Hi everyone! (KATHRYN looks to JI-SOO to say hello, but JI-SOO doesn't say anything.)

KATHRYN: First let's get to know everyone's names, I'm Kathryn. (KATHRYN looks to JI-SOO.)

JI-SOO: I'm Ji-soo

KATHRYN: What are your names? (The students go around the circle and say their names.)

KATHRYN: Nice to meet you everyone! Let's start our first drama game - What should we play Ji-Soo?

JI-SOO: (somewhat timidly) How about pass the energy?

KATHRYN: Great! (There is a prolonged pause as KATHRYN waits to see if JI-SOO will take the lead, JI-SOO doesn't.)

KATHRYN: Okay, this is how you play. . . (explains and starts the game. After a few moments of the game...)

JI-SOO: And stop! (The group stops and everyone looks expectantly at JI-SOO. But JI-SOO looks at KATHRYN. Awkward pause.)

Ji-Soo's lack of confidence reflected in this scene represents the reluctance of some ELL Program Leaders to initiate or lead drama activities. Prior to the first visit at Cedar Springs, some Program Leaders expressed anxiety about their ability to communicate with the elementary students, especially when trying to explain activities. However, after the first session, one ELL Program Leader reflected that the self-doubt was "baseless anxiety . . . there was not any barrier between kids and me" (Mi-Lei, Program Leader journal 2008). The increase of confidence expressed by the ELL Program Leaders was reflected in a similar growth among the ELL students: 
There was a little boy who initially told us that he wouldn't be able to do the drama activities if there was any reading involved because he is ESL! In the end, he turned out to be one of the most enthusiastic participants! (Mary, Program Leader journal 2008)

While language proficiencies and cultural differences at times hindered participants' comfort, the use of drama often helped transcend linguistic barriers to draw the ELL participants into the dramatic community. Through drama activities, students had the opportunity to "get to know one another and really express themselves without the constraints of language" (Sanya, Program Leader journal 2008).

\section{Issues in Scripting the Data}

The researchers began the journey of scripting the data by individually reading the Program Leaders' journals while searching for common and outlying themes to use as a basis for scene development. While developing and analyzing these themes towards a script, the authors had to decide whether to use the data verbatim or write new text based upon the data. Saldaña (1999) suggests that when developing research-based theatre, authors should not "compose what [their] participants tell you in interviews. [But to] creatively and strategically edit their stories" (1999: 64). However, the researchers found that enacting the verbatim language of the ELL participant journals produced potentially "stereotypical, discriminatory and destructive representations" (Goldstein 2002: 7), especially since they were all non-ELL performers. Hence, the authors decided against using the language found in the journals verbatim; scenes were inspired by themes within the data, but written in their own words. For example, the text below is taken verbatim from a Korean Program Leader journal:

I heard sentence from a girl next to me, but I had no idea what it was. However, the girl was smiling as if too easy not to miss. It was just because of language ability. From then, I didn't feel good and confidence was lost (Yeun-ha, Program Leader journal 2008).

The scripted text, below, attempted to capture the essence (Beare \& Belliveau 2008: 145) of the data in a theatrical form while reducing possible stereotypical interpretation:

(M.J. whispers the sentence to KATHRYN who smiling, whispers it to JI-SOO. JI-SOO listens, looking panicked; all but JI-SOO freeze.)

JI-SOO: The whisper game is pretty fun. We all laughed at the differences between our original sentence and what resulted. But when the sentence was whispered to me, I had no idea what it was. The person who whispered it to me had this smile like it was too easy. Everyone was laughing at how we mixed up this simple sentence, but I was nervous. It looked like it was fun for everyone else, but for me . . . I lost my confidence. 


\section{Researcher Reflections}

Just as a tension between process and product was suggested within the Program Leader journals, a tension was also reflected in the researchers' attempts to create a performance (or product) that was aesthetically convincing for the intended audiences. In the development of the research-based theatre piece, it was discovered that the understandings gained through the process of creation were stronger than the aesthetic quality of the final product. Like the Program Leaders, the process and product were influenced by the researchers' diverse experiences: their histories and identities as artists, researchers, and teachers continuously shaped their interpretation and dissemination of data (Irwin \& Springgay 2008).

The research-based theatre presentation sought to share both insights gained from the data and the theatre-based process used to explore the data. Ultimately the researchers' own meta-reflections were woven into the presentation along with slides and non-dramatized discussions of the study's context and theoretical underpinnings. The process of creating this inter-textual presentation proved challenging because of the high-level of collaboration required. At times, the process resembled the Program Leaders' cautious lead-taking during the after-school drama program. For instance, early in the development process the researchers met to improvise the created scenes; however, instead of jumping directly into the warm-ups, they hesitated: "there was a palpable awkwardness and silence that lasted for about ten seconds. We were [silently] negotiating who would lead the activities" (Researcher reflection 2009). ${ }^{5}$ The hesitancy or slight tension within the group continued through the development process as each researcher approached the work from their unique perspective. However, through these tensions, creation emerged, as revealed in one of the researcher's journal reflection:

We worked all day at UBC today. I think that we got a lot done. However, sometimes I feel like we are not all on the same page and that we are always afraid of stepping on each other's toes. I guess that is only to be expected though. You can't always expect that everyone is going to be on the same page. It just doesn't work like that. Conflict arises or simple differences and often times that is where creation comes from. (Researcher reflection 2009)

\section{Conclusion: Explorations of Drama as an Additional Language}

The findings within the research point to ways in which drama can create community with a group of multicultural and multilingual learners. While working together towards a specific goal, whether within the process of one

\footnotetext{
${ }^{5}$ Researcher reflections are taken from notes made by the researchers/authors while developing the research-based theatre presentation.
} 
afternoon or towards the final product at the end of the after-school drama program, a community was created independent of the levels of language involved. At times, language proficiencies and cultural differences did impede the participants' comfort levels, yet the use of drama was able to bridge cultural and linguistic barriers. The activities of the after-school drama program were also beneficial to the ELL students and Program Leaders as confidence and their perception of their language fluency and accuracy were further developed during communication with group members in improvisations and rehearsed presentations, times when community building was created through shared challenges.

The findings within the research reflect how within the created community in the after-school drama program, socially responsible behaviour between the ELL and non-ELL students and Program Leaders developed. In the ELL Program Leaders' journals individuals express how they were able to explore new social contexts and environments through the program, aiding them in understanding the new culture that they were living in.

The richness and playfulness the authors were afforded, by analyzing the data through theatre and later developing a presentation using theatre-based approaches to disseminate the data, shed light on the challenges and benefits of collaborative endeavours. In the spirit of the overarching aim of this research building community through drama - the authors/researchers, along with the Cedar Spring students and UBC Program Leaders, experienced the potential that drama and theatre have for creating cohesive communities. Through critical self-reflection and the written feedback gathered from conference audiences, the authors aim to provoke new meaning (Irwin \& Springgay 2008) as they further explore Drama as an Additional Language. ${ }^{6}$

\section{Bibliography}

Axtmann, Ann (2002): Transcultural Performance in Classroom Learning. In: Gerd Bräuer (ed.): Body and Language: Intercultural Learning through Drama. Westport, CT: Ablex, 37-50

Beare, David; Belliveau, George (2008): Dialoguing Scripted Data. In: Stephanie Springgay, Rita Irwin, Carl Leggo, Peter Gouzouasis (eds.): Being with A/r/tography. Rotterdam: Sense Publishers, 141-149

Belliveau, George et. al. (2008): [Addressing the Role of the Bystander through Drama in Bullying Situations] Unpublished raw data

Bolton, Gavin (1979): Towards a Theory of Drama in Education. London: Longman.

Bolton, Gavin (1984): Drama as Education: An Argument for Placing Drama at the Centre of the Curriculum. London: Longman

\footnotetext{
${ }^{6}$ Special thank you to Vince White, Ahava Shira and Ladda Prasertsintanah for their contributions to the project, as well as to the Program Leaders, elementary students, and Cedar Springs staff and administration.
} 
Bournot-Trites, Monique; Belliveau, George; Spiliotopoulos, Valia; Séror, Jeremie (2007): The Role of Drama on Cultural Sensitivity, Motivation and Literacy in a Second Language Context. In: Journal for Learning through the Arts: A Research Journal on Arts Integration in Schools and Communities 3/1, 1-35

Bowell, Pamela; Heap, Brian (2001): Planning Process Drama. London: David Fulton

Bräuer, Gerd (2002): Body and Language: Intercultural Learning through Drama. Westport, CT: Ablex Pub

Bruner, Jerome (1996): The Culture of Education. Cambridge, MA: Harvard University Press

Catterall, James (2002): Drama. In: Richard J. Deasy (ed.): Critical Links: Learning in the Arts and Student Academic and Social Development. Washington, DC: Arts Education Partnership, Council of Chief State School Officers (CCSSO), 29-72

Cook, Henry Caldwell (1917): The Play Way. London: Heineman

Dodson, Sarah L (2000): FAQs: Learning Languages through Drama. In: Texas Papers in Foreign Language Education 5/1, 129-141

Donaldson, Margaret (1978): Children's Minds. London: Fontana

Fels, Lynn; Belliveau, George (2008): Performative Inquiry: Curricular Explorations through Role Drama. Vancouver: Pacific Educational Press

Frasier, Debra (1991): On the day You Were Born. New York: Harcourt Inc.

Freire, Paulo (1998): Pedagogy of the Oppressed. Translated by Myra Bergman Ramos. New York: Herder \& Herder

Goldstein, Tara (2001): Hong Kong, Canada: Playwrighting as Critical Ethnography. In: Qualitative Inquiry, 7/3, 279-303

Goldstein, Tara (2002): Performed Ethnography for Representing Other People's Children in Critical Educational Research. In: Applied Theatre Researcher 5/3, 1-10

Heathcote, Dorothy; Bolton, Gavin (1995): Drama for Learning: Dorothy Heathcote's Mantle of the Expert Approach to Education. Portsmouth, N.H.: Heinemann

Hsieh, Hsieu-Fang; Shannon, Sarah E. (2005): Three Approaches to Qualitative Content Analysis. In: Qualitative Health Research 15/9, 1277-1288

Irwin, Rita; Springgay, Stephanie (2008): A/r/tography as Practice-based Research. In: Stephanie Springgay, Rita Irwin, Carl Leggo, Peter Gouzouasis (eds.): Being with $A / r /$ tography. Rotterdam: Sense Publishers, xix-xxxiii

McKean, Barbara (2006): A Teaching Artist at Work. Portsmouth, NH: Heinemann

Miccoli, Laura (2003): English through Drama for Oral Skills Development. In: ELT Journal 57/2, 122-128 
Mienczakowski, Jim; Moore, Teresa (2008): Performing Data with Notions of Responsibility. In: Gary Knowles \& Ardra Cole (eds.): Handbook of the Arts in Qualitative Research. Thousand Oaks, CA: Sage Publications, 451-458

Norris, Joe (2000): Drama as Research: Realizing the Potential of Drama in Education as a Research Methodology. In: Youth Theatre Journal 14, 40-51

O'Neill, Cecily (1995): Drama Worlds: A Framework for Process Drama. Portsmouth, NH: Heinemann

Raczuk, Helen; Smith, Marilyn (2000): The Gentle People: An Animal Tale from Argentina (adapted). In: Helen Raczuk \& Marilyn Smith (eds.): Invitation to Readers Theatre: Celebrating Stories of our Canadian Heritage. Spruce Grove, Alberta: U-Otter-Read-It Press, 25-26

Rohd, Michael (1998): Theatre for Community, Conflict, and Dialogue: A Hope is Vital Training Manual. Portsmouth, NH: Heinemann

Saldaña, Johnny (1998): Ethical Issues in an Ethnographic Performance Text: The 'Dramatic Impact' of 'Juicy Stuff.' In: Research in Drama Education 3/2, 181-196

Saldaña, Johnny (1999): Playwriting with Data: Ethnographic Performance Texts. In: Youth Theatre Journal 13, 60-71

Saldaña, Johnny (2003): Dramatizing Data: A Primer. In: Qualitative Inquiry 9/2, 218-236.

Saldaña, Johnny (2005): An Introduction to Ethnodrama. In: Johnny Saldaña (ed.): Ethnodrama: An Anthology of Reality Theatre. Walnut Creek, CA: AltaMira Press, 1-38

Schewe, Manfred (2002): Teaching Foreign Language Literature: Tapping the Students' Bodily-kinesthetic Intelligence. In: Gerd Bräuer (ed.): Body and Language: Intercultural Learning through Drama. Westport, CT: Ablex, 73-94

Slade, Peter (1954): Child drama. London: University of London

Vygotsky, Lev (1978): Mind in Society: The Development of Psychological Processes. Cambridge, MA: Harvard University Press

Wagner, Betty Jane (1998): Educational Drama and Language Arts: What Research Shows. Portsmouth, NH: Heinemann

Ward, Winnifred (1939): Theater for Children. New York: Appleton-Century

Way, Brian (1967): Development through Drama. Atlantic Highlands, NJ: Humanities 